\title{
Responsabilidad estatal por violencia de género: comentarios sobre el caso "Campo Algodonero" en la Corte Interamericana de Derechos Humanos
}

Este comentario, junto a los documentos que analiza, está disponible en www.anuariocdh.uchile.cl

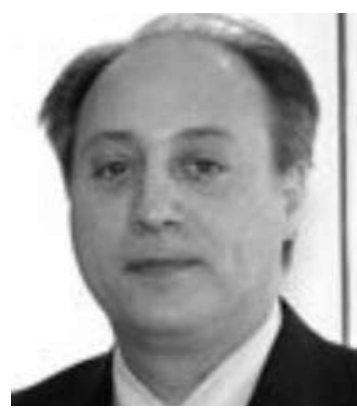

\begin{abstract}
Víctor Abramovich
Abogado, egresado con diploma de honor de la Universidad de Buenos Aires (UBA). Obtuvo una Maestría en Derecho Internacional (LL.M.) en el Washington College of Law de la American University. En junio de 2005 fue electo miembro de la Comisión Interamericana de Derechos Humanos de la OEA por el periodo 2006-2010, siendo Relator Especial sobre Derechos de las Mujeres. Profesor de la Facultad de Derecho de la Universidad de Buenos Aires (UBA) y Director de la Maestría en Derechos Humanos de la Universidad Nacional de Lanús (UNLA). abramovichv@gmail.com
\end{abstract}

\section{RESUMEN}

El artículo analiza la violencia de género y su relación con la discriminación estructural, y los distintos modelos de imputación de responsabilidad internacional del Estado por actos de terceros que se desprenden de los precedentes de la Corte Interamericana de Derechos Humanos, en la sentencia del Caso González y otras (Campo Algodonero) vs. México.

\section{Introducción}

El caso denominado "Campo Algodonero" ${ }^{1}$ es un precedente paradigmático en el desarrollo de la jurisprudencia del sistema interamericano de derechos humanos (SIDH). Por primera vez, la Corte Interamericana de Derechos Humanos (Corte IDH o Corte) examina una situación estructural de violencia contra las mujeres basada en su género, esto es, el tipo de violencia que define el artículo primero de la Convención de Belém do Pará (CBDP)². En su sentencia la Corte IDH concluye que los homicidios de las tres víctimas definidas en el caso, Laura Berenice Ramos, Claudia

1 Corte IDH, Caso González y otras (Campo Algodonero) vs. México. Sentencia de 16 de noviembre de 2009. Para el análisis de este caso hemos considerado además la demanda de la CIDH y el escrito de solicitudes, argumentos y pruebas de los peticionarios. Ver Demanda de la CIDH ante la Corte Interamericana de Derechos Humanos en el caso de Campo Algodonero: Claudia Ivette González, Esmeralda Herrera Monreal y Laura Berenice Ramos Monárrez (Casos 12.496, 12.497 y 12.498) contra los Estados Unidos Mexicanos, 4/11/ 2007. Escrito presentado a la Corte IDH, por Josefina González, Benita Monárrez e Irma Monreal Jaime, y por el Centro de Desarrollo Integral de la Mujer (CEDIMAC), la Red Ciudadana de No Violencia y Dignidad Humana, la Asociación Nacional de Abogados Democráticos A. C. (ANAD) y el Comité de América Latina y el Caribe para la Defensa de los Derechos de la Mujer (CLADEM). También se consultó la contestación de demanda de México ante la Corte.

2 El artículo 1 de la CBDP define la violencia contra las mujeres como "cualquier acción o conducta, basada en su género, que causa muerte, daño o sufrimiento físico, sexual o sicológico a la mujer, tanto en su ámbito público como en el privado". Cabe mencionar que en un caso previo, la Corte IDH examinó los alegatos de las partes sobre violación del derecho a la integridad física usando como criterio de interpretación el artículo 7 de la CBDP. Ver Corte IDH, caso del Penal de Castro Castro. Sentencia de 25 de noviembre de 2005, Serie C, No. 160, párr. 276. 
Ivette González y Esmeralda Herrera Monreal, fueron cometidos "por razones de género", esto es, constituyen casos de "feminicidio"3 ${ }^{3}$ y están enmarcados dentro de un contexto de violencia contra las mujeres en Ciudad Juárez ${ }^{4}$.

La Corte define con cierta precisión el estándar de "debida diligencia" establecido en el artículo 7 de la CBDP, a fin de determinar el alcance del deber estatal de prevención de crímenes basados en el género, tales como desapariciones, vejaciones sexuales, torturas y homicidios de mujeres. En el caso, la Corte aplica el estándar de debida diligencia respecto del deber estatal de protección de los derechos frente a actos de particulares.

También fija la Corte los criterios jurídicos que permiten atribuir esos crímenes de particulares al Estado. La definición de un campo de responsabilidad jurídica estatal por crímenes de particulares es un tema espinoso en un contexto regional atravesado por crisis políticas recurrentes, causadas por el creciente deterioro de la seguridad ciudadana. El caso se refiere además a hechos ocurridos en una de las ciudades más violentas del continente.

En Campo Algodonero, el tribunal interamericano retomó la doctrina del riesgo previsible y evitable -inspirada en la jurisprudencia del sistema europeo de derechos humanos-, que había desarrollado en fallos previos relacionados con prácticas de violencia de grupos paramilitares en el conflicto armado interno en Colombia. En esta ocasión aplicó esos estándares al contexto social de prácticas de violencia contra las mujeres en Ciudad Juárez, definiendo un deber de protección estatal reforzado por la CBDP.

La Corte IDH examinó la situación de las tres víctimas, no sólo en función de los hechos particulares que rodearon sus desapariciones y los procesos penales en que se investigaron los crímenes, sino como miembros de un colectivo más amplio que se ve afectado por una situación estructural de violencia y desigualdad, lo que permite entender los crímenes particulares en su real dimensión. De allí que la decisión de la Corte en este caso profundiza una línea jurisprudencial sobre igualdad estructural que se asienta ya en varios precedentes de la propia Corte y de la CIDH. Esta tendencia jurisprudencial del SIDH reafirma la existencia de deberes de acción positiva para los Estados en la protección de colectivos expuestos a patrones de discriminación y violencia. En estos precedentes la CIDH y la Corte han considerado especialmente datos del contexto social de las víctimas y su integración a colectivos o grupos sociales discriminados, para definir el alcance de las obligaciones estatales de respeto, garantía y protección.

En este breve comentario del caso vamos a focalizar el análisis en la definición del deber de debida diligencia en la protección de la violencia de género cometida por actores no estatales. Para ello, procuraremos primero ubicar el caso de estudio en la tendencia jurisprudencial del SIDH sobre igualdad y en especial sobre protección de grupos sometidos a patrones estructurales de violencia y discriminación. Sobre el final analizaremos los principales fundamentos de la decisión de la Corte IDH en "Campo Algodonero" sobre la imputación de responsabilidad estatal por los crímenes, e intentaremos caracterizar las diferentes doctrinas usadas en el SIDH sobre el tema.

\section{Igualdad estructural y deber de protección ante prácticas de violencia}

La perspectiva histórica sobre la jurisprudencia del SIDH marca en nuestra opinión una evolución desde un concepto de igualdad formal, elaborado en la etapa de las transiciones a la democracia

\footnotetext{
3 La Corte afirma que utilizará la expresión: "homicidio de mujeres en razón de género también conocido como feminicidio". Ver Corte IDH, caso Campo Algodonero, párrafo 143.

4 Corte IDH, caso Campo Algodonero, párrafo 231.
} 
en los países de América Latina, hacia un concepto de igualdad sustantivo que se comienza a consolidar en la última década, luego del fin de las transiciones, cuando la temática de la discriminación estructural y los derechos de los grupos discriminados se presentan con más fuerza en el tipo de casos y asuntos considerados por el SIDH. Así, se avanza desde una idea de igualdad entendida como no discriminación, hacia una noción de igualdad como la protección de grupos subordinados. Eso significa que se evoluciona desde una noción clásica de igualdad, que apunta a la eliminación de privilegios o de diferencias irrazonables o arbitrarias, que busca generar reglas iguales para todos, y demanda del Estado una suerte de neutralidad o "ceguera" frente a la diferencia. Y se desplaza hacia una noción de igualdad sustantiva, que demanda del Estado un rol activo para generar equilibrios sociales, la protección especial de ciertos grupos que padecen procesos históricos o estructurales de discriminación. Esta última noción presupone un Estado que abandone su neutralidad y que cuente con herramientas de diagnóstico de la situación social para saber qué grupos o sectores deben recibir en un momento histórico determinado medidas urgentes y especiales de protección.

En un informe reciente de la $\mathrm{CIDH}$ se sistematizan algunas decisiones jurisprudenciales del sistema que marcan esta evolución en el concepto de igualdad en relación con los derechos de las mujeres ${ }^{5}$.

Entre los sectores mencionados por el SIDH como grupos discriminados o excluidos que requieren protección especial o tratamiento diferenciado se encuentran los pueblos indígenas ${ }^{6}$ o la población afrodescendiente ${ }^{7}$ y las mujeres en relación al ejercicio de ciertos derechos, como la protección frente a la violencia ${ }^{8}$ y la participación política ${ }^{9}$. También se ha enfatizado la obligación de garantía de los Estados ante la existencia de grupos en situación de vulnerabilidad, como los niños que viven en la vía pública, o en sistemas de internación, los enfermos mentales en reclusión, los inmigrantes indocumentados, la población campesina desplazada de sus territorios, o las personas pobres portadoras de VIH/ SIDA, entre otros.

El concepto de igualdad sustantiva incide en la forma en que el SIDH ha comenzado a releer las obligaciones de los Estados en materia de derechos civiles y políticos en ciertos contextos sociales, por ejemplo, el derecho a la vida, a la integridad física, a la participación política y a la protección judicial, entre otros.

$5 \mathrm{CIDH}$, "El Acceso a la Justicia para las Mujeres Víctimas de Violencia en las Américas", 20 de enero de 2007, pp. 33-51.

6 Sobre las obligaciones positivas de los Estados de garantizar el ejercicio de ciertos derechos civiles, políticos y sociales por los miembros de las comunidades indígenas, en la Corte IDH pueden revisarse los casos: Masacre de Plan Sánchez Vs. Guatemala. Fondo. Sentencia de 29 de abril de 2004. Serie C, No. 105; Comunidad Moiwana Vs. Suriname. Excepciones Preliminares, Fondo, Reparaciones y Costas. Sentencia 15 de junio de 2005. Serie C, No. 124, y Comunidad Indígena Yakye Axa Vs. Paraguay. Fondo, Reparaciones y Costas. Sentencia 17 de junio de 2005. Serie C, No. 125. Recientemente este principio llevó a la Corte a reinterpretar las obligaciones del Estado respecto del derecho a la vida hasta incorporar un deber de garantizar ciertos mínimos vitales de salud, agua y educación, vinculados con el derecho a la vida digna de una comunidad indígena expulsada de su territorio colectivo, en el caso Comunidad Indígena Sawhoyamaxa Vs. Paraguay. Fondo, Reparaciones y Costas. Sentencia de 29 de marzo de 2006. Serie C, No. 146, y las subsiguientes decisiones de supervisión de sentencia. La Corte también fijó el alcance del deber de consulta y búsqueda de consentimiento en relación con actividades económicas que pudieran afectar recursos, territorios y recursos naturales de los pueblos indígenas, en el Caso del Pueblo Saramaka Vs. Surinam. Excepciones Preliminares, Fondo, Reparaciones y Costas. Sentencia de 28 de noviembre de 2007. Serie C, No. 172.

7 Ver el caso Simona André Diniz contra Brasil, Informe 37/02 declarado admisible por la CIDH en el que se alega incumplimiento del deber estatal de protección frente a conductas discriminatorias de particulares, basadas en el color o la raza.

8 Sobre la obligación de adoptar políticas y medidas positivas para prevenir, sancionar y erradicar la violencia contra las mujeres, puede verse el Informe 54/01, Maria Da Penha Maia Fernandez contra Brasil, del 16 de abril de 2001.

9 Ver CIDH Informe 103/01, "María Merciadri de Moroni."Argentina, del 11 de octubre de 2001, sobre cupos en el sistema electoral argentino. 
Así, la Corte estableció, por ejemplo, la obligación de los Estados de adoptar medidas positivas para garantizar que los pueblos indígenas puedan participar, en condiciones de igualdad, en la toma de decisiones sobre asuntos y políticas que inciden o pueden incidir en sus derechos y en el desarrollo de dichas comunidades, de forma tal que puedan integrarse a las instituciones y órganos estatales y participar de manera directa y proporcional a sus poblaciones en la dirección de los asuntos públicos, así como hacerlo desde sus propias instituciones políticas y de acuerdo a sus valores, usos, costumbres y formas de organización. La Corte, en la sentencia dictada en el caso Yatama ${ }^{10}$, consideró que la legislación nicaragüense sobre monopolio de partidos políticos y las decisiones de los órganos electorales del Estado, habían limitado irrazonablemente la posibilidad de participación en un proceso electoral de una organización política representativa de las comunidades indígenas de la costa atlántica del país. Este caso, también en nuestra opinión, expresa la afirmación del principio de igualdad estructural, pues la Corte IDH obliga al Estado a flexibilizar la aplicación de las normas electorales de alcance general para adecuarlas a las formas de organización política que expresan la identidad cultural de un grupo. En definitiva, lo que la Corte reconoce es un "derecho especial o diferenciado a favor de un grupo"11 que fija ciertas "protecciones externas" al grupo minoritario, que se consideran indispensables para la preservación de su autonomía política, pero también aseguran su participación en la estructura institucional del Estado nacional.

La noción de igualdad material o estructural parte del reconocimiento de que ciertos sectores de la población están en desventaja en el ejercicio de sus derechos por obstáculos legales o fácticos y requieren, por consiguiente, la adopción de medidas especiales de equiparación. Ello implica la necesidad de trato diferenciado, cuando debido las circunstancias que afectan a un grupo desaventajado, la identidad de trato suponga coartar o empeorar el acceso a un servicio o bien, el ejercicio de un derecho. También conduce a examinar la trayectoria social de la supuesta víctima, el contexto social de aplicación de las normas o las políticas cuestionadas, así como la situación de subordinación o desventaja del grupo social al cual pertenecen los potenciales afectados ${ }^{12}$.

El empleo de la noción de igualdad material conlleva una definición sobre el rol del Estado como garante activo de los derechos, en escenarios sociales de desigualdad. Es además una herramienta útil para examinar las normas jurídicas, las políticas públicas y las prácticas estatales, tanto su formulación, como sus efectos. Además tiene consecuencias directas en el debate sobre remedios efectivos, pues es sabido que las obligaciones positivas son más difíciles de exigir, por ejemplo, por

10 Corte IDH, Caso Yatama Vs. Nicaragua. Excepciones Preliminares, Fondo, Reparaciones y Costas. Sentencia de 23 de junio de 2005. Serie C, No. 127. En esta sentencia la Corte comienza a definir el alcance del derecho a la participación política consagrado en el artículo 23 de la Convención Americana y considera que comprende, además de la participación en procesos electorales formales, la participación en otros mecanismos de discusión y fiscalización de políticas públicas. También se procura avanzar en la sentencia en mayores precisiones sobre el alcance de la obligación estatal de garantizar este derecho de participación respecto de sectores sociales excluidos o que se encuentran en situación de desventaja en el ejercicio de este derecho. Para ello el tribunal vincula el derecho a la igualdad, entendido como igualdad no sólo formal sino sustantiva, con el derecho de asociación y de participación política. Ver en tal sentido el voto concurrente del juez Diego García Sayan. Para entender mejor el sentido que la propia Corte IDH le da a su decisión en Yatama, se sugiere leer también como lo diferencia de un caso posterior sobre exclusión de candidaturas independientes, considerando especialmente en Yatama la existencia de un grupo subordinado o discriminado con características de identidad cultural diferenciadas. Ver Corte IDH, Caso Castañeda Gutman Jorge vs. Estados Unidos Mexicanos, 6 de agosto de 2008. Párrafo 172.

11 Ver al respecto, KYMLICKA, W. Nacionalismo Minoritario dentro de las Democracias Liberales. En: GARCÍA, S. y LUKES, S. Ciudadanía: Justicia Social, Identidad y Participación. Madrid, Siglo XXI Editores, 1999. También KYMLICKA, W. Ciudadanía Multicultural. Barcelona, Paidós. 1996.

12 Para un análisis de las nociones de igualdad como reconocimiento de derechos diferenciados a ciertos grupos, puede verse además de KYMLICKA, W. op. cit., YOUNG, I.M. Vida Política y Diferencia de Grupo. En: CASTELLS, C. (Comp.). Perspectivas Feministas en Teoría Política. Madrid, Editorial Paidós, 1996, p. 120; FISS, O. Grupos y la Cláusula de Igual protección. En: Gargarella, R. (comp). Derecho y grupos desaventajados. Barcelona, 1999, pp. 137-167. 
la vía judicial doméstica. En especial cuando se exigen comportamientos positivos para resolver conflictos de naturaleza colectiva.

Además, la noción de igualdad sustantiva se proyecta sobre el deber estatal de proteger a grupos sociales discriminados frente a ciertas prácticas y patrones de violencia que los afectan. Estas prácticas son el resultado de patrones de discriminación y relaciones asimétricas de poder en la sociedad, y suelen contribuir a reproducir y reforzar las desigualdades en ámbito social, cultural y político.

La CIDH consideró especialmente el impacto diferenciado sobre ciertos grupos sociales de prácticas extendidas de violencia desarrolladas por agentes estatales o por actores no estatales con la connivencia o tolerancia del Estado. En este orden de ideas, la Comisión, por ejemplo, estableció la responsabilidad de Brasil por no haber adoptado medidas para prevenir los desalojos forzosos violentos emprendidos por ejércitos privados de hacendados que eran expresión de un patrón sistemático de violencia rural tolerado por las autoridades estatales, seguido de un patrón de impunidad en las investigaciones criminales de estos hechos. Para eso la CIDH tuvo especialmente en cuenta la situación de desigualdad estructural en que se encuentra un sector de la población rural en ciertos estados del Norte brasileño, y los niveles de tolerancia y connivencia entre sectores poderosos de hacendados, las fuerzas policiales y la justicia estadual ${ }^{13}$. En otro caso, la CIDH responsabilizó a Brasil por un patrón de violencia policial dirigido a jóvenes negros en las favelas de Río de Janeiro, considerando que la ejecución extrajudicial de un joven de este grupo social era un hecho representativo de ese patrón, el cual a su vez expresaba un sesgo racista en la actuación de la fuerza pública estadual, con la complicidad de la autoridad federal ${ }^{14}$. También la CIDH y la Corte IDH consideraron la situación de vulnerabilidad diferenciada frente a la violencia política de ciertos grupos en el marco del conflicto armado interno en Colombia, imponiendo al Estado deberes específicos de protección que implican restricciones en el uso de la propia fuerza estatal, y protección especial frente a otros actores no estatales, así como obligaciones especiales de reparación de alcance colectivo y políticas sociales diferenciadas y culturalmente pertinentes. Estas medidas de protección parten de la obligación de respetar y garantizar ciertos derechos culturales de grupos étnicos, por ejemplo, restricciones a determinadas actividades bélicas en resguardo de la integridad de territorios colectivos de pueblos indígenas y comunidades negras colombianas ${ }^{15}$.

\section{Deber de protección y violencia de género}

Podemos señalar algunos antecedentes importantes del SIDH sobre el alcance de la obligación de protección ante violencia de género cometida por actores no estatales, que están presentes en la base argumental del caso que comentamos.

En el caso de María Da Penha Maia Fernández contra Brasil, la CIDH, aplicó por primera vez la CBDP y fijó deberes especiales de protección estatal vinculados con el derecho a la vida y a la integridad física, en función de una interpretación del principio de igualdad en línea con la que

$13 \mathrm{CIDH}$, Informe 25/09, "Sebastiao Camargo Filho". Brasil, del 19 de marzo de 2009.

$14 \mathrm{CIDH}$, Informe 26/09, "Wallace de Almeida". Brasil, del 20 de marzo de 2009.

15 Pueden consultarse las medidas provisionales de la Corte IDH, en el caso del Pueblo Kankuamo y de las comunidades afrocolombianas del Jiguamiandó y el Curbaradó, entre muchas otras. Ver además, para ilustrar el tipo de situaciones colectivas mencionadas en el marco del conflicto armado colombiano, $\mathrm{CIDH}$; "Informe sobre la visita al terreno en relación con las medidas provisionales ordenadas a favor de los miembros de las comunidades constituidas por el Consejo Comunitario del Jiguamiandó y las familias del Curbaradó, Municipio del Carmen del Daríen, Departamento del Chocó, República de Colombia", noviembre de 2008. 
expusimos. Frente a un patrón estructural de violencia doméstica que afectaba a las mujeres de la ciudad de Fortaleza en el Estado de Ceará, acompañada por una práctica general de impunidad judicial frente a este tipo de casos criminales, y la negligencia del gobierno local en implementar medidas efectivas de prevención, estableció que el Estado federal había violado las garantías judiciales y la obligación de actuar con debida diligencia para asegurar la integridad física de la peticionaria y su igualdad ante la ley. También estableció que los Estados tienen un deber de acción preventiva diligente para evitar prácticas de violencia contra las mujeres, aun frente a la actuación de actores no estatales, con base no sólo en el artículo 7 de la CBDP sino también en la propia Convención Americana. La responsabilidad del Estado provenía de no haber adoptado medidas preventivas con debida diligencia para evitar que esa forma extendida de violencia existiera y se reprodujera en perjuicio de un grupo o colectivo determinado, además de la falta de respuesta efectiva frente a les lesiones graves sufridas por la víctima a manos de su esposo, quien estaba sujeto a un proceso que llevaba 15 años sin juicio.

La CIDH valoró fundamentalmente en el caso Maria Da Penha la existencia de un patrón o "pauta sistemática" en la respuesta estatal, que expresa a su juicio una suerte de tolerancia pública con la situación de violencia denunciada, no sólo en perjuicio de la víctima, sino con relación a otros casos idénticos o con características comunes. Es más, para la $\mathrm{CIDH}$, la inefectividad judicial discriminatoria crea un ambiente que favorece la violencia doméstica que sufren las mujeres.

El enfoque, como dijimos, va más allá de la situación particular de la víctima individual, pues se proyecta a la evaluación de la situación de discriminación y subordinación de un grupo social determinado. La situación estructural del grupo de mujeres afectadas por la violencia, por un lado califica los deberes de prevención del Estado y sus obligaciones reparatorias en el caso particular, pero además justifica el tipo de recomendaciones de alcance general que fija la CIDH al Estado y que incluyen, por ejemplo, cambios en las políticas públicas, en la legislación y en los procedimientos judiciales y administrativos ${ }^{16}$.

Para la CIDH no sólo se ha violado en el caso la obligación de investigación y remedio de prácticas de violencia domésticas basadas en el género, sino también el deber de previsión. Sin embargo, en el análisis que realiza la $\mathrm{CIDH}$ no queda claro si se refiere a la imposibilidad del Estado de prever el desarrollo de la práctica generalizada de violencia que afecta a las mujeres en el Estado de Ceará, o a la imposibilidad del Estado de prevenir la agresión de la que fuera objeto la víctima del caso. No existe en Maria Da Penha una discusión particular, ni alegatos de los peticionarios, sobre si agentes del Estado demandado contaban con información adecuada sobre el riesgo existente para la vida y la integridad de la víctima antes de que se consumara la agresión, o si estaban en condiciones de evitarla razonablemente.

\section{El caso Campo Algodonero}

En Campo Algodonero la Corte decide analizar la situación de las tres víctimas individuales del caso en función de un contexto de violencia contra un grupo social al cual las víctimas pertenecían. Este examen, en contexto de la situación de las víctimas particulares, es indispensable para la determinación del alcance de la responsabilidad del Estado por crímenes que habrían sido cometidos según la prueba disponible, por actores no estatales.

La Corte considera que puede generarse responsabilidad internacional para el Estado por atribución a éste de actos cometidos por terceros o particulares, en el marco de las obligaciones

16 CIDH, Informe 54/01,"Maria Da Penha Maia Fernández. Brasil, del 16 de abril de 2001. 
del Estado de garantizar el respeto de esos derechos entre individuos ${ }^{17}$. En este sentido, la Corte Interamericana ha considerado en varios precedentes que la obligación de garantía y respeto de los derechos humanos se proyectan más allá de la relación entre sus agentes y las personas sometidas a su jurisdicción, pues se manifiestan también en la obligación positiva del Estado de adoptar las medidas necesarias para asegurar la efectiva protección de los derechos en las relaciones entre los individuos. La atribución de responsabilidad al Estado por actos de particulares puede darse cuando el Estado incumple, por acción u omisión de sus agentes, con esta función de protección, pero sólo en aquellas circunstancias particulares en que se considere que los agentes estatales cumplían una posición de garantes con relación a la acción de particulares ${ }^{18}$.

Los criterios para la atribución de responsabilidad al Estado por el incumplimiento de un deber de protección no son claros en la jurisprudencia de la Corte, y en nuestra opinión suelen aparecer confusamente mezclados con otro factor de atribución de responsabilidad más directo, que es el apoyo o tolerancia con la acción de un actor no estatal. Este último criterio implica complicidad estatal con la violación de derechos y se ha utilizado en casos de acciones de grupos paramilitares que actúan bajo la protección de aparatos gubernamentales, e incluso bajo el amparo de normas jurídicas formales ${ }^{19}$. La doctrina de la complicidad (apoyo o tolerancia) atribuye responsabilidad objetiva al Estado como si la acción del particular hubiese sido ejecutada por un agente estatal de manera directa.

El análisis de la Corte en "Campo Algodonero", toma como base para atribuir responsabilidad al Estado por la acción de particulares, la doctrina del riesgo previsible y evitable. Esta teoría, que surge en el sistema europeo de derechos humanos, es incorporada por la Corte en algunos precedentes relativos a la violencia paramilitar en el conflicto armado interno colombiano, en los que se cuestionaba la evidencia sobre complicidad directa de agentes públicos. En estos precedentes la Corte desarrolla la idea de un deber estatal de debida diligencia para la protección de los derechos frente a ciertas situaciones de riesgo para su ejercicio. No se trata de atribuir responsabilidad estatal frente a cualquier violación de derechos humanos cometida entre particulares en su jurisdicción. El deber del Estado de adoptar medidas de prevención y protección está condicionado, según la Corte, por el conocimiento de una situación de riesgo real e inmediato para un individuo o grupo de individuos determinado, y por la posibilidad razonable de prevenir o evitar ese riesgo ${ }^{20}$.

17 Sobre las doctrinas de atribución de responsabilidad internacional a los Estados por actos de particulares, puede verse, BROWNLIE, Ian. Principles of Públic International Law. Fifth Edition, Oxford University Press, 1998, Part VII, pp. 435476; CHAPHAM, Andrew. Human Rights in the Private Sphere. Clarendon Press-Oxford, 1996, pp. 178-244.

18 Caso de la Masacre de Mapiripán Vs. Colombia. Excepciones preliminares. Sentencia 7 de marzo 2005. Serie C, No. 122, párr. 111, párr. 112; Caso de la Comunidad Moiwana Vs. Surinam. Excepciones Preliminares, Fondo, Reparaciones y Costas. Sentencia 15 de junio de 2005. Serie C, No. 124, párr. 211; Caso Tibi Vs. Ecuador. Excepciones Preliminares, Fondo, Reparaciones y Costas. Sentencia de 7 de septiembre de 2004. Serie C, No. 114; Caso de los Hermanos Gómez Paquiyauri Vs. Perú. Fondo, Reparaciones y Costas. Sentencia de 8 de julio de 2004. Serie C, No. 110, párr. 91; Caso 19 Comerciantes Vs. Colombia. Fondo, Reparaciones y Costas. Sentencia de 5 de julio de 2004. Serie C, No. 109, párr. 183; Caso Maritza Urrutia Vs. Guatemala. Fondo, Reparaciones y Costas. Sentencia de 27 de noviembre de 2003. Serie C, No. 103, párr. 71; Caso Bulacio Vs. Argentina. Fondo, Reparaciones y Costas. Sentencia de 18 de septiembre de 2003. Serie C, No. 100, párr. 111, y Caso Juan Humberto Sánchez Vs. Honduras. Excepción Preliminar, Fondo, Reparaciones y Costas. Sentencia de 7 de junio de 2003. Serie C, No. 99, párr. 81.

19 Ver Corte IDH, Caso de la "Panel Blanca" (Paniagua Morales y otros). Sentencia de 8 de marzo de 1998, Serie C, No. 37, párr. 91.

20 Corte IDH, Caso de la Masacre de Pueblo Bello. Sentencia de 31 de enero de 2006. Serie C, No. 140 párrs. 123 y 124. En tal sentido, el tribunal sigue la jurisprudencia de la Corte Europea, la que afirma: "No todo alegado riesgo a la vida impone a las autoridades la obligación convencional de tomar medidas operativas para prevenir que aquel riesgo llegue a materializarse. Para que surja la obligación positiva, debe ser establecido que al momento de los hechos las autoridades sabían, o debían haber sabido, de la existencia de un riesgo real e inmediato para la vida de un individuo identificado o de algunos individuos respecto de actos criminales de terceros, y que tales autoridades no tomaron las medidas dentro del alcance de sus poderes que, juzgadas razonablemente, podían esperarse para evitar el daño". 
La doctrina del riesgo requiere, en consecuencia, al menos la presencia en un caso de cuatro elementos: (i) que exista una situación de riesgo real o inmediato que amenace derechos y que surja de la acción o las prácticas de particulares; esto es, se requiere que el riesgo no sea meramente hipotético o eventual y además que no sea remoto, sino que tenga posibilidad cierta de materializarse en lo inmediato ${ }^{21}$. (ii) Que la situación de riesgo amenace a un individuo o a un grupo determinado, es decir, que exista un riesgo particularizado. Lo anterior supone un requisito más estricto que la sola existencia de un riesgo general o una situación extendida de inseguridad que afecta al conjunto de la comunidad. (iii) Que el Estado conozca el riesgo o hubiera debido razonablemente conocerlo o preverlo. En tal sentido aquí cuenta tanto la evidencia que determina que las agencias habían obtenido información sobre la situación de riesgo, como también la previsibilidad del riesgo, esto es, la posibilidad de establecer cierta presunción de conocimiento de ese riesgo a partir de las circunstancias del caso, y que está muchas veces asociada al rol de vigilancia o monitoreo que la propia Convención o la CBDP impone al Estado, como también con las características del riesgo. Así, los Estados tienen el deber impuesto por la Convención y por otros tratados y normas internas, de producir información y hacer seguimiento de la situación de violencia que sufren algunos grupos sociales y sectores de la población (ej. Violencia contra las mujeres, desplazados internos, prácticas de racismo) de modo que no puede admitirse como excusa el desconocimiento de situaciones de violencia en estos casos. Además, existen riesgos que son previsibles por su envergadura, por su extensión en el tiempo, porque obedecen a prácticas, por o patrones sistemáticos que hacen imposible su desconocimiento por la autoridad estatal. (iv) Finalmente, que el Estado pueda razonablemente prevenir o evitar la materialización del riesgo. Para poder imputar responsabilidad se requiere entonces primero que el riesgo sea por sus características evitable, y que el Estado esté en condiciones de adoptar medidas capaces de paliar la situación y evitar la materialización del riesgo. Este último elemento se refiere tanto a las características de los factores de riesgo que se presentan, como a las capacidades operativas de los agentes públicos que podían actuar en ese escenario determinado. A su vez, las capacidades operativas no corresponden sólo a la situación subjetiva de los agentes frente a la situación particular, sino que pueden estar a su vez condicionadas por aspectos más generales que suelen determinar la idoneidad de las respuestas estatales, tales como la insuficiencia del sistema legal, o el déficit de las políticas públicas, o la debilidad de las agencias competentes. La posibilidad del Estado de evitar la consumación del riesgo es un elemento conflictivo del estándar. Muchas veces la dificultad de actuar deriva del incumplimiento de obligaciones impuestas por la Convención, que imponen al Estado una posición de garante de derechos frente a ese tipo de riesgo, por ejemplo, la falta de adecuación legislativa en materia de discriminación racial o violencia de género, o la ineficacia de los sistemas remediales en la administración de justicia que el Estado debe disponer como tutela judicial efectiva. Es razonable afirmar que el Estado no podrá invocar la imposibilidad de prevenir la consumación de un riesgo, si ha contribuido a ello por no adoptar medidas de garantía que la propia Convención establecía.

Así, un factor que complejiza aún más el criterio del riesgo es que los Estados no son, por lo general, sujetos pasivos que intentan paliar riesgos sociales que les son ajenos, sino que contribuyen con sus acciones, sus políticas, sus prácticas y sus omisiones, a la creación, configuración

Corte Europea de Derechos Humanos, Kilic. V. Turkey, sentencia del 28 de marzo de 2000. Aplication No. 22492/93, párrs. 62-63; Osman Vs. United Kingdom, sentencia del 28 de octubre de 1998.

21 Sobre el concepto de "riesgo real e inmediato" y el deber de protección por acciones de particulares en manifestaciones públicas, puede verse, Corte IDH. Caso Ríos y otros Vs. Venezuela. Excepciones Preliminares, Fondo, Reparaciones y Costas. Sentencia de 28 de enero de 2009. Serie C, No. 194, párr. 110. Caso Perozo y otros Vs. Venezuela. Excepciones Preliminares, Fondo, Reparaciones y Costas. Sentencia de 28 de enero de 2009. Serie C, No. 195, párr. 121. Ver también voto concurrente de Diego García Sayán en Campo Algodonero, párrs. 8, 9 y 10. 
o consolidación de las situaciones de riesgo social, aun cuando la situación riesgosa provenga de conductas criminales de particulares.

La doctrina de la complicidad apunta a establecer una responsabilidad directa del Estado por la acción de tolerancia, aquiescencia o apoyo de agentes públicos con los crímenes de actores no estatales. En tal sentido, la acción del particular se asimila a efectos de la responsabilidad internacional con acciones de agentes públicos. En el otro extremo, la doctrina del riesgo apunta a una responsabilidad estatal indirecta por incumplimiento del deber de garantía, que incluye una obligación específica de previsión y protección frente a actos de particulares.

Pero la Corte ha desarrollado en algunos casos una teoría intermedia para aquellos en que si bien no es posible afirmar que agentes públicos han sido cómplices de un acto violatorio de derechos humanos, la participación del Estado no se limita a un incumplimiento de deberes de protección, e incluye acciones públicas, normas, prácticas o políticas, que han creado objetivamente la situación de riesgo. Cuando el Estado ha creado el riesgo sus deberes de garantía frente a actos de particulares son más estrictos. A esta tercera doctrina de atribución de responsabilidad podría denominarla para ordenar las ideas aquí expuestas, como doctrina del riesgo creado, pues el Estado está obligado a proteger frente a un riesgo que él mismo creó, y tiene un deber particular de desactivar la situación de riesgo que ha engendrado directamente.

Así, en una serie de casos relacionados con crímenes de lesa humanidad cometidos por grupos paramilitares colombianos en un período en el que el accionar de estos grupos había sido ilegalizado, y en los cuales la Corte no encontró prueba directa de complicidad en esos casos entre paramilitares y agentes públicos, el tribunal impuso responsabilidad al Estado por incumplimiento de sus deberes de garantía, sobre la base de una aplicación particular de la teoría del riesgo, pero considerando que existía un deber agravado de protección en razón de que el Estado había creado la situación de riesgo y no había logrado luego desactivarla. Así dijo la Corte: "[d]e lo anterior se desprende que el Estado propició la creación de grupos de autodefensas con fines específicos, pero éstos se desbordaron y empezaron a actuar al margen de la ley. Al respecto, la Corte ha observado que dichos "grupos paramilitares son responsables de numerosos asesinatos [...] y de una gran parte de las violaciones de derechos humanos en general" cometidas en Colombia. Además, se ha demostrado ante este Tribunal "la existencia de numerosos casos de vinculación entre paramilitares y miembros de la fuerza pública en relación con hechos similares a los ocurridos en el presente caso, así como actitudes omisivas de parte de integrantes de la fuerza pública respecto de las acciones de dichos grupos". En tales casos, el Tribunal ha declarado la responsabilidad internacional del Estado colombiano por haber incumplido "con su obligación de garantizar los derechos humanos [y, en ese sentido,] haber faltado a sus deberes de prevención y protección" 22 .

En algunos casos la Corte consideró que la creación de la situación de riesgo por haber propiciado la conformación de grupos paramilitares había sido un aporte estatal decisivo para agravar la situación de vulnerabilidad, frente de violencia de un grupo social determinado, como los defensores de derechos humanos en Colombia:

"Al respecto, la Corte ha señalado anteriormente que, 'al haber propiciado la creación de estos grupos [de autodefensas,] el Estado creó objetivamente una situación de riesgo para sus habitantes y no adoptó todas las medidas necesarias ni suficientes para evitar que éstos siguieran cometiendo hechos como los del presente caso'. La Corte reconoce, como lo ha hecho en otras ocasiones, que

22 Corte IDH. Caso Valle Jaramillo y otros Vs. Colombia. Fondo, Reparaciones y Costas. Sentencia de 27 de noviembre de 2008. Serie C, No. 192, párr. 76. 
si bien el Estado ha adoptado determinadas medidas legislativas para prohibir, prevenir y castigar las actividades de los grupos de autodefensa o paramilitares, esas medidas no se vieron traducidas en la desactivación concreta y efectiva del riesgo que el propio Estado había contribuido a crear. Por tanto, dicho riesgo, mientras subsista, 'acentúa los deberes especiales de prevención y protección a cargo del Estado en las zonas en que exista presencia de grupos paramilitares [...]'. El Tribunal considera que dicho riesgo generado por el Estado agravó la situación de vulnerabilidad de las defensoras y defensores de derechos humanos que, como Jesús María Valle Jaramillo, denunciaban las violaciones cometidas por paramilitares y la fuerza pública" ${ }^{\prime 2}$.

De modo que entre la doctrina de la complicidad, y la doctrina del riesgo, podemos ubicar esta tercera doctrina del riesgo creado. Claro que quedaran zonas grises, por ejemplo, cuando el Estado no haya creado directamente la situación de riesgo, pero haya contribuido de manera decisiva a crearla o mantenerla por el incumplimiento de deberes de protección y garantía impuestos por el derecho internacional de los derechos humanos. No es equivalente a la creación objetiva del riesgo (como en el caso colombiano por la sanción de leyes que autorizan a actuar a grupos paraestatales), pero sí define de alguna manera la participación estatal en la configuración de los factores institucionales y sociales de los que proviene el riesgo, a raíz del incumplimiento de deberes convencionales de debida diligencia, e incluso de deberes de debida diligencia agravados o reforzados en ciertos contextos.

En tal sentido, el grado de contribución estatal a la existencia o persistencia del riesgo será un factor decisivo para evaluar los requisitos de evitabilidad y previsibilidad del riesgo, en una situación determinada.

Corresponde en lo que sigue analizar brevemente los criterios de atribución de responsabilidad usados por la Corte en el caso "Campo Algodonero".

La demanda de la CIDH y el escrito de los peticionarios ante la Corte plantean con matices la hipótesis de que la situación de riesgo a evitar obedecía a un patrón de violencia, discriminación e impunidad, que afectaba a las mujeres jóvenes de sectores pobres de Ciudad Juárez. Que ese patrón se había comenzado a configurar a partir de la comisión de crímenes basados en el género, que incluían homicidios, desapariciones, torturas y vejámenes sexuales, desde fines de la década del noventa. Sostienen además que el Estado no era sólo responsable de no haber previsto o evitado los crímenes, sino que había contribuido sustancialmente a la configuración de ese patrón de violencia, tanto por la falta de políticas de seguridad dirigidas a la protección de las mujeres, como por la falta de respuesta del sistema de justicia para buscar a las mujeres secuestradas y para investigar diligentemente los crímenes ya consumados. Sostenían que la respuesta estatal deficitaria no era sólo resultado de la negligencia y la imprevisión, sino de patrones de discriminación y machismo arraigado en las agencias públicas. En tal sentido, podría afirmarse, que tanto la CIDH como los peticionarios plantean una participación clara del Estado en la configuración y preservación de la situación de riesgo que lleva a la muerte de las víctimas. Ello pese a que no hay acuerdo entre la CIDH y los peticionarios sobre el momento exacto en que se configura responsabilidad del Estado por las violaciones consumadas. Para la $\mathrm{CIDH}$, si bien el Estado es responsable de la configuración del patrón de violencia, sólo resulta jurídicamente imputable la responsabilidad internacional a partir de que toma conocimiento de las desapariciones de

23 Corte IDH. Caso Valle Jaramillo y otros Vs. Colombia. Fondo, Reparaciones y Costas. Sentencia de 27 de noviembre de 2008. Serie C, No. 192, párr. 80 y 81; Caso de las Masacres de Ituango Vs. Colombia. Excepción Preliminar, Fondo, Reparaciones y Costas. Sentencia de 1 de julio de 2006 Serie C, No. 148; Caso de la Masacre de Pueblo Bello Vs. Colombia. Interpretación de la Sentencia de Fondo, Reparaciones y Costas. Sentencia de 25 de noviembre de 2006. Serie C, No. 159; Caso de la Masacre de Mapiripán Vs. Colombia. Fondo, Reparaciones y Costas. Sentencia de 15 de septiembre de 2005. Serie C, No. 134. 
las tres víctimas y no actúa eficazmente para evitar sus homicidios y los crímenes que sufren en cautiverio. Para los peticionarios la responsabilidad internacional se genera un paso antes, por la falta de prevención de las desapariciones de las mujeres, que no son más que la expresión de un patrón de violencia que afecta a todo el grupo ${ }^{24}$.

La Corte no adhiere a la teoría del patrón sistemático de violencia, y parece optar por una imputación atenuada de responsabilidad estatal basada en la doctrina del riesgo, pero con el componente particular de la existencia en el caso de un deber de debida diligencia reforzado en función del artículo 7 de la CBDP. Lamentablemente la Corte no describe de manera precisa los criterios de atribución de responsabilidad que usa en el caso, combinando citas jurisprudenciales que refieren tanto a lo que denominamos doctrina de la complicidad ${ }^{25}$, como de la doctrina del riesgo previsible y evitable ${ }^{26}$.

De la lectura de la decisión, me inclino a pensar que es este último el criterio que finalmente prevalece en el análisis de la evidencia. Así, la Corte considera que el artículo 7 de la CBDP, establece un deber de debida diligencia reforzado, lo que parece indicar que este opera estableciendo una carga adicional de deberes de prevención al Estado, por sobre un piso de debida diligencia en la protección de las acciones de particulares, que vendría dado, en principio, por la propia Convención Americana. Aunque en el razonamiento de la sentencia no queda claro cual sería el piso de debida diligencia, y qué elementos adicionales agregaría la norma especial de la CBDP, la Corte define algunos puntos que serán valiosos en el examen final sobre la imputación de responsabilidad. Sostiene la Corte que:

"Los Estados deben adoptar medidas integrales para cumplir con debida diligencia en casos de violencia contra las mujeres. En particular, deben contar con un adecuado marco jurídico de protección, con una aplicación efectiva del mismo, con políticas de prevención y prácticas que permitan actuar de una manera eficaz ante las denuncias. La estrategia de prevención debe ser integral, es decir, debe prevenir los factores de riesgo y a la vez fortalecer las instituciones para que puedan proporcionar una respuesta efectiva de los casos de violencia contra la mujer. Asimismo, los Estados deben adoptar medidas preventivas en casos específicos en los que es evidente que determinadas mujeres y niñas pueden ser víctimas de violencia. Todo esto debe tomar en cuenta que en casos de violencia contra la mujer, los Estados tienen, además de las obligaciones genéricas contenidas en la Convención Americana, una obligación reforzada a partir de la Convención de Belém do Pará" 27.

La definición que realiza la Corte de los contenidos básicos del deber de debida diligencia con base en el artículo 7 de la CBDP tiene indudable impacto en la aplicación de la doctrina del riesgo, pues implica colocar al Estado en una posición de garante respecto del riesgo de violencia basada en el género.

Así, el deber de debida diligencia agravado incide en la previsibilidad del riesgo de violencia basada en el género, pues el deber de prevención de factores de riesgo obliga al Estado a realizar un monitoreo de la situación social de violencia. La CIDH ha establecido que:

24 Ver demanda de la CIDH, párrs. 161-176. Ver Escrito de los Peticionarios, página 133. Señalan los peticionarios: "Las autoridades mexicanas al momento en que ocurrieron las desapariciones de las víctimas tenían conocimiento de que existía un riesgo real e inmediato para la vida de estas. Debido a que los casos aquí expuestos forman parte del patrón de violencia contra mujeres, niñas, y el Estado no tomó las medidas necesarias con la debida diligencia para evitarlo".

25 Corte IDH, Caso Campo Algodonero, párr. 236.

26 Corte IDH, Caso Campo Algodonero, párr. 280.

27 Corte IDH, Caso Campo Algodonero, párr. 258. 
"El deber de debida diligencia para prevenir situaciones de violencia, sobre todo en el contexto de prácticas extendidas o estructurales, impone a los Estados el correlativo deber de vigilar la situación social mediando la producción de información estadística adecuada que permita el diseño y la evaluación de las políticas públicas, así como el control de las políticas que se implementen por parte de la sociedad civil. En tal sentido la obligación del artículo 7 inc. B de la Convención de Belém do Pará debe ser interpretada en conjunción con la obligación establecida en el artículo 8 inciso H de garantizar la investigación y recopilación de estadísticas y demás información pertinente sobre las causas, consecuencias y frecuencias de la violencia contra las mujeres, con el fin de evaluar la eficacia de las medidas para prevenir, sancionar y eliminar la violencia contra las mujeres y de formular e introducir los cambios necesarios" ${ }^{28}$.

En tal sentido, a fin de considerar la previsibilidad de un riesgo de violencia contra las mujeres en una situación particular, debe partirse de considerar que el propio Estado tiene un deber de monitoreo y evaluación de la situación de violencia de género, que lo hace responsable de la ausencia de datos sociales fiables. En ese sentido, podríamos considerar que el deber reforzado de debida diligencia en la CBDP actúa imponiendo un esfuerzo adicional relacionado con el conocimiento de las situaciones de riesgo y, por lo tanto, limita considerablemente el margen del Estado para invocar su desconocimiento en una situación particular.

Por otro lado, el deber de debida diligencia reforzado parece operar también sobre la evitabilidad del riesgo, esto es, sobre los factores que contribuyen a prevenir la materialización del riesgo y que están según la Corte en la órbita del propio Estado. Por ejemplo, la necesaria adecuación de los marcos normativos, la implementación de políticas generales de protección, la implementación de estrategias para superar la desigualdad de poder y la discriminación de las mujeres, y la efectividad de los mecanismos de tutela judicial, entre otros. También en este punto, la capacidad operativa del Estado de evitar que se materialice una situación de riesgo, no puede ser observada como si el Estado fuera un sujeto extraño al riesgo que debe reaccionar cuando lo conoce con lo que tiene disponible. El déficit de las políticas públicas y del sistema institucional determina en gran medida la capacidad de respuesta en la situación particular. También aquí está en cabeza del Estado contar con un sistema adecuado de reacción frente a este tipo de riesgos, y por lo tanto el margen para alegar la inevitabilidad de un riesgo se reduce considerablemente.

En Campo Algodonero resulta clara la vinculación entre el incumplimiento de los deberes de adopción de políticas públicas, de mecanismos idóneos y efectivos de protección judicial y de adecuación normativa, con las circunstancias que contribuyen a que las agencias públicas no logren prever ni evitar los crímenes. Por ejemplo, la $\mathrm{CIDH}$, los peticionarios y la propia Corte señalan cómo prejuicios machistas en los propios operadores judiciales demoraron el inicio de las averiguaciones del paradero de las jóvenes desaparecidas. También se identificó cómo resultaron determinantes de la impunidad de los crímenes de las víctimas y de las demás mujeres afectadas por formas similares de violencia en Ciudad Juárez, las irregularidades cometidas por los jueces, policías locales y peritos forenses que realizaron autopsias y examinaron el lugar donde aparecen los cuerpos ${ }^{29}$.

El otro aspecto relevante en Campo Algodonero es la característica del riesgo que debe ser evaluado en el examen de imputación de responsabilidad estatal por actos de particulares. Como

$28 \mathrm{CIDH}$, Informe: "El Acceso a la Justicia para las Mujeres Víctimas de Violencia en las Américas", 20 de enero de 2007, párr. 42.

29 Ver, por ejemplo, descripción de irregularidades en pericias forenses realizadas a las víctimas del caso y a otras víctimas encontradas en el denominado "Campo Algodonero" y "Cristo Negro" en escrito de Solicitudes de los peticionarios, pp. 108-111. 
dijimos, si bien la Corte no adhiere a la tesis del patrón sistemático, brinda vital importancia a la existencia de un contexto social de violencia que presenta aspectos particulares en Ciudad Juárez. La Corte afirma:

“De todo lo expuesto anteriormente, la Corte concluye que desde 1993 existe en Ciudad Juárez un aumento de homicidios de mujeres, habiendo por lo menos 264 víctimas hasta el año 2001 y 379 hasta el 2005. Sin embargo, más allá de las cifras, sobre las cuales la Corte observa no existe firmeza, es preocupante el hecho de que algunos de estos crímenes parecen presentar altos grados de violencia, incluyendo sexual, y que en general han sido influenciados, tal como lo acepta el Estado, por una cultura de discriminación contra la mujer, la cual, según diversas fuentes probatorias, ha incidido tanto en los motivos como en la modalidad de los crímenes, así como en la respuesta de las autoridades frente a éstos. En este sentido, cabe destacar las respuestas ineficientes y las actitudes indiferentes documentadas en cuanto a la investigación de dichos crímenes, que parecen haber permitido que se haya perpetuado la violencia contra la mujer en Ciudad Juárez. La Corte constata que hasta el año 2005 la mayoría de los crímenes seguían sin ser esclarecidos, siendo los homicidios que presentan características de violencia sexual los que presentan mayores niveles de impunidad" ${ }^{30}$.

El contexto de violencia configura para la Corte una situación general que incide sobre la situación particular de las víctimas y sobre el tipo de respuestas que debía brindar el Estado. Se trata de una suerte de "riesgo general" que a su vez califica la expectativa de respuesta del Estado ante el "riesgo particularizado" de cada una de las tres víctimas del caso. El riesgo general contribuye a definir las características de previsibilidad y evitabilidad del riesgo particular.

Para la Corte existen dos momentos claves en los que debe examinarse el deber de prevención estatal. El primero antes de la desaparición de las víctimas, y el segundo luego de la desaparición y antes de la localización de sus cuerpos sin vida.

Respecto del primer momento la Corte concluye que existe una falta del Estado en el cumplimiento general de su obligación de prevención. Sin embargo, ello no conduce a determinar la responsabilidad internacional del Estado porque, a pesar de que éste tenía conocimiento de una situación de riesgo para las mujeres de Ciudad Juárez, no ha sido establecido que tuviera conocimiento de un riesgo real e inmediato para las víctimas del caso. Esto es, tenía conocimiento del riesgo general de violencia de género, pero no sobre el riesgo particularizado de las víctimas individuales. De esa manera, la Corte marca un límite a la aplicación de la doctrina del riesgo, pues es estricta en exigir un conocimiento directo de un riesgo particularizado que afecte de manera concreta a una víctima determinada. El riesgo general genera deberes de acción, pero su incumplimiento no es suficiente, según la Corte, para atribuir responsabilidad al Estado por todo lo sucedido a cada una de las víctimas.

Es recién en un segundo momento, luego de la desaparición y antes del hallazgo de los cuerpos, que para la Corte el Estado tuvo ya un conocimiento de la existencia de un riesgo real e inmediato para la vida e integridad física de las víctimas individuales. Este conocimiento se define no sólo por la prueba sobre la información que tenía el Estado respecto de la desaparición de cada una de las víctimas individuales al momento de su ocurrencia, sino también en función del contexto social descrito, de violencia extendida contra las mujeres ${ }^{31}$.

30 Corte IDH, Caso Campo Algodonero, párr. 164.

31 Corte IDH, Caso Campo Algodonero, párrs. 282 y 283. 
La Corte, así, agrava el deber de debida diligencia, o dicho en otros términos, somete su cumplimiento a un estándar más estricto en el caso, en función del contexto de violencia de género, considerando especialmente cómo ese contexto debió orientar las acciones estatales. De alguna manera, como dijimos, el riesgo general verificado en el caso incide sobre la posibilidad de prever y evitar el riesgo particularizado, esto es, los crímenes sufridos por las víctimas. Dice la Corte:

"La Corte considera que ante tal contexto surge un deber de debida diligencia estricta frente a denuncias de desaparición de mujeres, respecto a su búsqueda durante las primeras horas y los primeros días. Esta obligación de medio, al ser más estricta, exige la realización exhaustiva de actividades de búsqueda. En particular, es imprescindible la actuación pronta e inmediata de las autoridades policiales, fiscales y judiciales ordenando medidas oportunas y necesarias dirigidas a la determinación del paradero de las víctimas o el lugar donde puedan encontrarse privadas de libertad. Deben existir procedimientos adecuados para las denuncias y que éstas conlleven una investigación efectiva desde las primeras horas. Las autoridades deben presumir que la persona desaparecida está privada de la libertad y sigue con vida hasta que se ponga fin a la incertidumbre sobre la suerte que ha corrido" ${ }^{32}$.

La Corte concluye que el Estado no ha demostrado haber adoptado medidas razonables conforme a las circunstancias del caso, para encontrar a las mujeres secuestradas y evitar sus muertes. Las investigaciones realizadas luego de anoticiada la desaparición fueron rituales e inefectivas, y los funcionarios desconfiaron de las versiones de las familias y negaron la urgencia de los casos, sin considerar el contexto de violencia que debía llevar a presumir que la vida de las jóvenes estaba en peligro inminente.

Como dijimos, la falta de respuesta de los agentes públicos en el caso se relaciona en parte con la falta de adopción de políticas más generales de prevención. La Corte señala:

"Además, la Corte considera que el Estado no demostró haber adoptado normas o implementado las medidas necesarias, conforme al artículo 2 de la Convención Americana y al artículo 7.c de la Convención Belém do Pará, que permitieran a las autoridades ofrecer una respuesta inmediata y eficaz ante las denuncias de desaparición y prevenir adecuadamente la violencia contra la mujer. Tampoco demostró haber adoptado normas o tomado medidas para que los funcionarios responsables de recibir las denuncias tuvieran la capacidad y la sensibilidad para entender la gravedad del fenómeno de la violencia contra la mujer y la voluntad para actuar de inmediato" ${ }^{\prime 3}$.

\section{Algunas conclusiones}

Si bien en Campo Algodonero la Corte extendió el alcance de la responsabilidad indirecta del Estado por la acción de particulares que tiene como consecuencia jurídica la violación de derechos humanos, también acotó el campo de responsabilidad estatal indirecta, al definir aunque de manera un tanto imprecisa todavía, algunos criterios de atribución de responsabilidad. Estos criterios están basados en los deberes genéricos de prevención de la Convención Americana, que operan como un piso, al que se agregan deberes "reforzados" de debida diligencia, que se originan en normas específicas relacionadas con la violencia basada en el género en razón del artículo 7 de la CBDP. También en nuestra opinión, estos deberes reforzados de protección surgen de la consideración especial que realiza la Corte del contexto de violencia y discriminación que afectaba en el caso al grupo social que integraban las víctimas, esto es, a las mujeres jóvenes de sectores pobres en Ciudad Juárez, lo que permitiría afirmar que este tipo de análisis de la doctrina

32 Corte IDH, Caso Campo Algodonero, párr. 283. Énfasis añadido.

33 Corte IDH, Caso Campo Algodonero, párr. 285. 
del riesgo podría ser aplicado en el futuro a la situación de otros grupos sociales afectados por patrones de violencia y discriminación.

La Corte fijó un límite en la atribución al Estado de crímenes de particulares, a partir de la exigencia de que éste tuviera conocimiento no sólo del riesgo general, sino de un riesgo particularizado, referido a una víctima o a un grupo de víctimas determinadas. Sólo a partir del conocimiento de ese riesgo particularizado (en el caso luego de la noticia sobre la desaparición de cada una de las víctimas), la Corte estuvo dispuesta a considerar que el Estado incumplió un deber concreto de actuación diligente, capaz de determinar su responsabilidad por crímenes de particulares ${ }^{34}$. Ello sin perjuicio de considerar que existía una obligación de prevención general relacionada con el contexto de violencia de género antes de la ocurrencia de las desapariciones de las víctimas.

Surge de la lectura del razonamiento de la Corte, que si en lugar de examinarse secuestros seguidos de muerte, se hubiera tratado de homicidios directos, el Estado hubiera sido en principio exonerado de su responsabilidad internacional. Aun cuando se hubiera concluido su contribución con la situación general de violencia. También que si las desapariciones de las tres víctimas hubieran sido hechos particulares y aislados y no parte de un contexto general, la Corte hubiera evaluado de una manera diferente la posible imputación al Estado de los casos. Quizá hubiera puesto más énfasis en el grado de información concreta con la que contaba el Estado respecto de cada hecho, a fin de prevenirlo o evitarlo.

Un factor que complica el análisis de la aplicación futura del precedente, es que la Corte además de utilizar la doctrina del riesgo, cita jurisprudencia referida a otros criterios de atribución de responsabilidad por actos de particulares, como es la doctrina que denominamos de la complicidad (apoyo o tolerancia estatal con el crimen). Por lo demás, la Corte incorpora el examen de las obligaciones del artículo 7 de la CBDP en el examen general sobre la obligación de prevención y protección. Por eso, si bien se refiere a que el artículo 7 de la CBDP fija un estándar reforzado de debida diligencia que opera sobre el estándar genérico de la Convención, no llega a definir en qué consiste el estándar genérico y qué cosas agrega en particular el estándar reforzado. En el análisis del caso hemos intentado responder a esta cuestión preliminarmente. Lo que ya es definitivo, es que ese deber de debida diligencia reforzado del artículo 7 de CBDP coloca al Estado en una posición de garante ante el riesgo de violencia basada en el género, y ello se refleja en el examen de los factores de previsibilidad y evitabilidad en la aplicación de la doctrina del riesgo como criterio de atribución de responsabilidad por actos de particulares.

Es difícil anticipar hasta dónde podría llegar la Corte en el futuro si se plantean, por ejemplo, nuevos casos de atribución de responsabilidad estatal por crímenes de particulares que no involucren violencia basada en el género de las víctimas.

Si bien es claro que en la evaluación de la situación particular de las víctimas del caso, la Corte consideró especialmente el contexto social y la situación de vulnerabilidad frente a la violencia del grupo social al que las víctimas pertenecían, al no establecerse una relación explícita en los

34 El razonamiento de la Corte en este punto coincide con la demanda de la CIDH. Si bien la CIDH planteó que existía un patrón sistemático de violencia e impunidad, sólo imputó responsabilidad al Estado por la falta de diligencia luego del conocimiento de las desapariciones, evaluando la conducta estatal también en función de su conocimiento de la existencia de un patrón de violencia en el cual debieron encuadrarse la ocurrencia de los crímenes. Los peticionarios coincidieron con la CIDH en señalar que existía un patrón sistemático de violencia, pero exigieron que se responsabilizara al Estado por no evitar y alimentar ese patrón, y en tal sentido, extendieron la atribución de responsabilidad por las desapariciones y no sólo por lo ocurrido luego de ellas. El Estado reconoció que existía un contexto de violencia contra las mujeres y el componente de género de algunos de los crímenes reconoció también algunas de las fallas denunciadas en la investigación penal de los crímenes de las tres víctimas, pero negó que de las circunstancias del caso derivaran elementos para atribuirle al Estado responsabilidad internacional por conductas de particulares. 
fundamentos de la sentencia, entre la situación de desigualdad del grupo y los deberes de prevención y protección, no es posible anticipar con certeza si los mismos criterios de atribución de responsabilidad que se usan en el caso serían aplicados por la Corte a situaciones similares de otros grupos sociales discriminados, que no fueran alcanzados por la Convención de Belém do Pará.

En nuestra opinión, más allá de la imprecisión de la sentencia en este punto, la condición de las víctimas como miembros de un grupo social afectado por un contexto persistente de violencia y discriminación es un factor clave del examen de la responsabilidad estatal en este caso, lo que debería permitir trasladar este precedente a otras situaciones similares de violencia sistemática o estructural contra grupos sociales desaventajados.

De alguna manera, el esquema de obligaciones de la Convención de Belém do Pará y en especial el deber de debida diligencia, sólo puede entenderse a partir de la relación que se establece en ese instrumento entre violencia y desigualdad. Las relaciones desiguales de poder son claves para entender la dinámica de la violencia de género y de allí la imposición al Estado de un deber de prevención y protección diferenciado o "reforzado" en palabras de la Corte. Esta conclusión ubica el caso que examinamos, en nuestra opinión, en la línea de una tendencia más amplia en el sistema interamericano en el tratamiento de cuestiones relacionadas con la protección especial y diferenciada de ciertos grupos sociales afectados por patrones de desigualdad. El Estado es garante de la igualdad, y por lo tanto tiene una posición de garante frente a patrones de violencia que afectan a grupos subordinados. Su deber de debida diligencia en la protección del grupo discriminado es, en consecuencia, un deber calificado o más intenso. La posición estatal de garante afecta fundamentalmente el examen de su capacidad o posibilidad de prevenir o evitar un riesgo real e inmediato contra el grupo o contra individuos del grupo. Conduce a ser menos rígido en el estudio de los requisitos de atribución del riesgo, y más estricto en la evaluación de las excusas del Estado.

Por último, me parece importante apuntar que los criterios usados por la Corte para definir los deberes positivos de prevención y protección del Estado frente a actos de particulares, a la luz de las obligaciones generales de garantía de la Convención y de las específicas de la CBDP, no resultan sólo fuente de responsabilidad internacional, sino que son criterios para imputar responsabilidad a los Estados en los sistemas jurídicos nacionales, donde ambos instrumentos se han incorporado como derecho doméstico, incluso en ocasiones con rango constitucional. Esto es, deberían tener un correlato en las doctrinas sobre responsabilidad administrativa por la prevención y reparación de daños causados por particulares.

Sin duda un tema pendiente es cómo profundizar la interpretación de estos principios a fin de alcanzar un mayor nivel de exigibilidad de estas obligaciones en los sistemas de justicia de los Estados, que deben brindar protección primaria y preferente antes de que un conflicto se convierta en un litigio internacional. Lamentablemente, existen pocos precedentes de decisiones de tribunales nacionales que declaren la operatividad y exigibilidad de las obligaciones positivas y de alcance general contenidas en el artículo 7 de la CDBP. Por ejemplo, la obligación de adoptar políticas públicas preventivas, regular mecanismos judiciales, y producir información estadística para el monitoreo de la situación social de violencia de género. Es posible que el precedente de la Corte en "Campo Algodonero" permita avanzar en esa dirección. 